\title{
$\mathrm{DyMnO}_{3}$ の過冷却融液からの急速凝固における核形成律速相 選択
}

\author{
早坂 燿 1 , 栗林一彦 2,3 白鳥 英 4 小澤俊平 5 \\ 1 千葉工業大学大学院工学研究科機械サイエンス専攻 \\ 2 宇宙航空研究開発機構宇宙科学研究所 \\ 3 千葉工業大学附属研究所 \\ 4 東京都市大学理工学部機械システム工学科 \\ 5 千葉工業大学工学部先端材料工学科
}

J. Japan Inst. Met. Mater. Vol. 85, No. 4 (2021), pp. 155-161

(C) 2021 The Japan Institute of Metals and Materials

\section{Nucleation-Controlled Phase Selection in Rapid Solidification from Undercooled Melt of $\mathrm{DyMnO}_{3}$}

You Hayasaka $^{1, *}$, Kazuhiko Kuribayashi ${ }^{2,3}$, Suguru Shiratori ${ }^{4}$ and Shumpei Ozawa ${ }^{5}$

${ }^{1}$ Graduate School of Engineering, Chiba Institute of Technology, Narashino 275-0016

${ }^{2}$ Institute of Space and Astronautical Science, Japan Aerospace Exploration Agency (JAXA), Sagamihara 252-5210

${ }^{3}$ Research Liaison Centre, Chiba Institute of Technology, Narashino 275-0016

${ }^{4}$ Department of Mechanical Systems Engineering, Faculty of Engineering, Tokyo City University, Tokyo 158-8557

${ }^{5}$ Department of Advanced Materials Science and Engineering, Faculty of Engineering, Chiba Institute of Technology, Narashino 275-0016

The crystal structure of $\mathrm{LnMnO}_{3}$ ( $\mathrm{Ln}$ : lanthanide) has been reported to be orthorhombic from La to Dy are used as Ln, and hexagonal from Ho to Lu. Whereas Kumar et al. reported that orthorhombic and hexagonal phases are co-exist in samples of $\mathrm{DyMnO}_{3}$ solidified from the undercooled melt under containerless state. We investigated whether this two-phases structure was the result that the hexagonal phase formed as a metastable phase is frozen to room temperature or the result that the solid state phase transformation of the hexagonal $\rightleftarrows$ orthorhombic occurred at the cooling stage.

The surface morphology of the samples, the nucleation of which were triggered by contacting with the Mo wire at given temperatures, indicates that hexagonal and orthorhombic phases are stable at high and low temperatures, respectively. Furthermore, in the experiment where the melt was dropped into water, it was found that if the temperature of the melt was below $1666 \mathrm{~K}$, the XRD pattern of the as-solidified sample showed two phases, $h-\mathrm{DyMnO}_{3}$ and $o-\mathrm{DyMnO}_{3}$, whereas above $1666 \mathrm{~K}$, it showed a single phase of $h$-DyMnO . This phenomenon can be quantified in terms of nucleation rate-determined phase selection. That is, the activation energy for nucleation calculated based on the model of the crystal-melt interface proposed by Turnbull and Spaepen suggests that the $o$ - $\mathrm{DyMnO}$ phase can be heterogeneously nucleated on the interface of the initially formed $h-\mathrm{DyMnO}{ }_{3}$ phase. [doi:10.2320/jinstmet.J2020061]

(Received December 18, 2020; Accepted January 15, 2021; Published February 26, 2021)

Keywords: phase selection, nucleation, undercooling, containerless processing, lanthanide manganite

\section{1. 緒言}

六方晶の希土類マンガン酸化物 $\left(h-\mathrm{LnMnO}_{3}, \mathrm{Ln}:\right.$ Lanthanide, space group: $P 6_{3} \mathrm{~cm}$ ) は, 強誘電性と(反) 強磁性を併せ持つマ ルチフェロイック特性 ${ }^{1-3)}$ を有することから，新しい記憶媒体 用の素子の候補として注目を集めている。しかし $\mathrm{LnMnO}_{3}$ 系 において六方晶を示すのは, Ln 元素がイオン半径の比較的 小さい Ho-Luに置換された場合であり，イオン半径が相対的 に大きい La-Dyに置換された場合では, 斜方晶 $\mathrm{LnMnO}_{3}(o-$ $\mathrm{LnMnO}_{3}$, space group: Pbnm) が安定相とされている4).この点 に関してKumarらは，ガスジェット浮遊炉を用いた過冷却融

\footnotetext{
* 千葉工業大学大学院生 (Graduate Student, Chiba Institute of Technology)
}

液からの凝固により, $\mathrm{DyMnO}_{3}$ 組成においては, $o-\mathrm{DyMnO}_{3}$

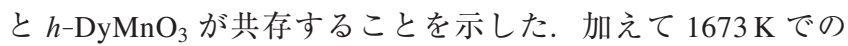
焼鈍を施すと, $o-\mathrm{DyMnO}_{3}$ 単相になることから，この共存の 理由は, $h-\mathrm{DyMnO}_{3}$ が準安定相として生成し, それが室温ま で残存するためであるとした5)（希土類元素をLn と記述した 場合 (例えば $h-\mathrm{LnMnO}_{3}$ ) は結晶構造 (この場合は六方晶)を表 す.また個々の元素を用いて，例えば $h-\mathrm{DyMnO}_{3}$ と記述した 場合は，組成が $\mathrm{DyMnO}_{3}$ の六方晶相を表す。なお， $h$-および $o$-を付けない場合は単に化学組成のみを表す).

Fig. 1 は液相から $o-\mathrm{DyMnO}_{3}$ と $h-\mathrm{DyMnO}_{3}$ が生成される場 合の, ギブスエネルギー $G$ と温度の関係を模したものであ る. Fig. 1(a) は, $o-\mathrm{DyMnO}_{3}$ の生成ギブスエネルギー $G_{o}$ が, $h-\mathrm{DyMnO}_{3}$ の生成ギブスエネルギー $G_{h}$ よりも低いものの, 核生成の点で有利な $h-\mathrm{DyMnO}_{3}$ が準安定相として生成する場 合である。（核生成の活性化エネルギーは，ギブスエネル 
ギー差よりも固液界面エネルギー $\gamma_{\mathrm{sl}}$ の影響を強く受ける. Turnbull $^{6)}$ と Spaepen ${ }^{7)}$ のデルに従えば, $\gamma_{\mathrm{sl}}$ は融解エントロ ピー差に依存し, 融解エントロピー差が小さい方が核生成に 有利に㗢くとされる. Fig. 1(a)の曲線の傾きは, エントロ ピーの大きさを意味しており, 液相のギブスエネルギーとの 傾き差の小さい $h-\mathrm{DyMnO}_{3}$ が核生成では有利となることが導 かれる)。実際に，同じ結晶構造の $\mathrm{LnFeO}_{3}$ 系では $h-\mathrm{LnFeO}_{3}$ の方が $o-\mathrm{LnFeO}_{3}$ よりも核生成が容易であると報告されてい $ろ^{8)}$

一方, 安定相が $h-\mathrm{LnMnO}_{3}$ から $o-\mathrm{LnMnO}_{3}$ に変化する $\mathrm{Ln}$ 元素の境界に当たる $\mathrm{DyMnO}_{3}$ について Szabo ら ${ }^{9)}$ は, 室温で 安定な $o-\mathrm{DyMnO}_{3}$ を約 $1873 \mathrm{~K}$ に加熱した結果, $h-\mathrm{DyMnO}_{3}$ へ変態したと報告している.これに基づくならば， $G_{o}$ と $G_{h}$ の交点である固相変態温度 $\left(T_{\mathrm{tr}}\right.$ : Transformation temperature $)$ よ りも低温では $o-\mathrm{DyMnO}_{3}$ が，高温では $h-\mathrm{DyMnO}_{3}$ が安定とな るため, 各相の $G$ と温度の関係は, Fig. 1(b)のようになるは ずである。この場合， $h-\mathrm{DyMnO}_{3}$ は準安定相ではなく，いわ ゆる高温相となることから，Kumar ら ${ }^{5)}$ が報告した $o-\mathrm{DyMnO}_{3}$ と $h-\mathrm{DyMnO}_{3}$ の共存は, 高温相と低温相の間の相変態が律速 する相選択の可能性がある

本研究ではこれらの観点から, $o-\mathrm{DyMnO}_{3}$ と $h-\mathrm{DyMnO}_{3}$ の 共存は両相の核生成頻度の違いによるものか, 両相間の相変 態によるものか，それとも他に原因があるのかを明らかにす ることを目的とした
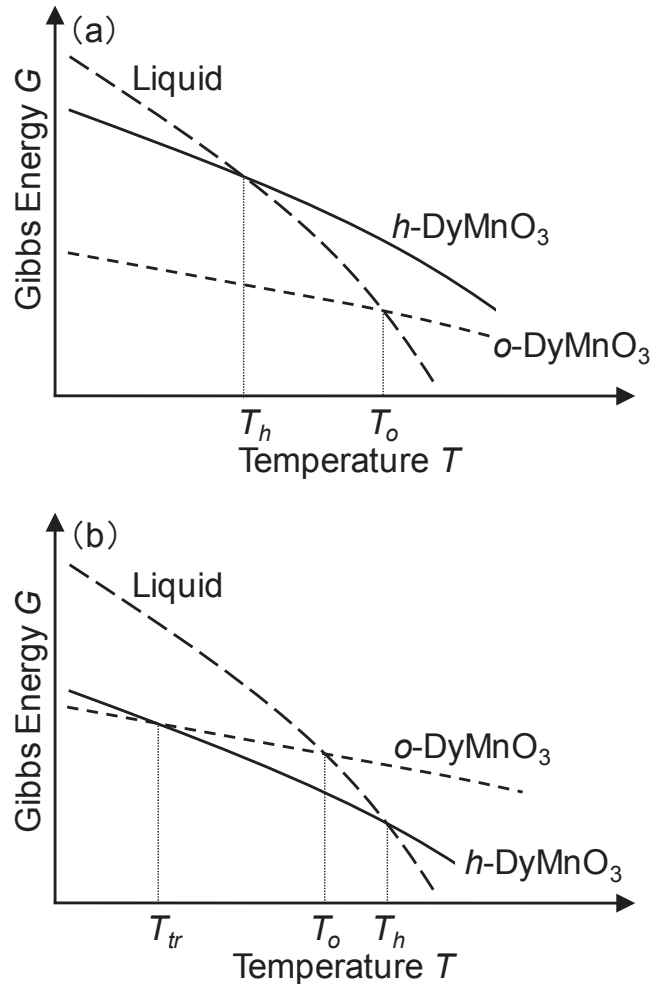

Fig. 1 Schematics of Gibbs energy for liquid, $h-\mathrm{DyMnO}$, and $o-\mathrm{DyMnO}_{3}$ as a function of temperature at constant pressure. (a) $G$ of $o-\mathrm{DyMnO}_{3}$ is lower than that of $h-\mathrm{DyMnO}_{3}$ and therefore they do not intersect. (b) $G$ of $o-\mathrm{DyMnO}_{3}$ is lower than that of $h-\mathrm{DyMnO}_{3}$ at low temperatures but higher at high temperatures. Therefore, the hypothetical melting point of $o-\mathrm{DyMnO}_{3}$ is lower than that of $h-\mathrm{DyMnO}_{3}$.

\section{2. 実 験 方 法}

質量純度が $99.9 \%$ 以上の $\mathrm{Dy}_{2} \mathrm{O}_{3}$ および $\mathrm{Mn}_{2} \mathrm{O}_{3}$ 粉末を秤量 し，瑪瑙乳鉢を用いて十分に混合した後，銅炉床上で半導体 レーザを照射して溶融し， $\mathrm{DyMnO}_{3}$ のバルク体を作製した. これを粉砕そして溶融・凝固を再び行うことで均質化を図 り, 約 $20 \mathrm{mg}$ (直径約 $2 \mathrm{~mm}$ ) の球状試料とした.この球状試料 を Fig. 2 に示すガスジェット浮遊炉(Aerodynamics levitation furnace: $\mathrm{ADL})^{8)}$ のノズルに載せ，マスフローコントローラ (MC-3102L-NC, (株)リンック)を用い，下部から酸素ガスを $\sim 600 \mathrm{~mL} / \mathrm{min}$ でフローして無容器浮遊させた。浮遊した試料 に, 上部から半導体レーザを照射して加熱・溶融させた後, レーザ照射の遮断によって冷却し，過冷凝固させた。また， 任意の過冷却度 $\Delta T$ で強制的に核生成させるために，浮遊液 滴への Mo ワイヤ (直径 $0.2 \mathrm{~mm}$ )の接触 (Fig. $2(\mathrm{a})$ ) や, 浮遊中 にガスジェットノズルを 2 分割して, 液滴の水中落下も行っ た(Fig. 2(b)).

浮遊試料の凝固挙動を, 高速度カメラ (HSV, FASTCAM MC-MP, (株)フトロン)により $2000 \mathrm{frames} / \mathrm{s}$ で記録した。ま たその際の温度履歴を, スポット径が $1.0 \mathrm{~mm}$ の単色放射温 度計(FTK9-P600A, ジャパンセンサー(株) を用いて, $2000 \mathrm{~Hz}$ で記録した。その際 $\mathrm{DyMnO}_{3}$ の放射率は, $\mathrm{LuFeO}_{3}$ の放射率 8 と同様に 0.9 とし，固相と液相で同じであると仮定した.

得られた試料の表面形態は，共焦点レーザ顕微鏡 (LSM, OPTELICS H1200，レーザーテック(株) を用いて観察した. また構成相は, $\mathrm{CuK}_{\alpha}$ 線を用いた粉末 $\mathrm{X}$ 線回折 $(\mathrm{XRD}$ MiniFlex600,(株リガク)により同定した。

3. 結果

$\mathrm{DyMnO}_{3}$ の過冷却融体における相選択が, $o-\mathrm{DyMnO}_{3} \rightleftarrows h-$ $\mathrm{DyMnO}_{3}$ の相変態に律速されるのか, それとも $o-\mathrm{DyMnO}_{3}$ と $h-\mathrm{DyMnO}_{3}$ の核生成頻度に律速されるのかを明らかにするた めに, 過冷した浮遊液滴に Mo ワイヤを接触させることで, 任意の過冷却度 $\Delta T$ で核生成させることを試みた。その代表 的な温度履歴と, 核生成時の外観を Fig. 3 に示す。浮遊溶融 させた試料をそのまま冷却すると (Fig. 3(a))，1545Kにおい

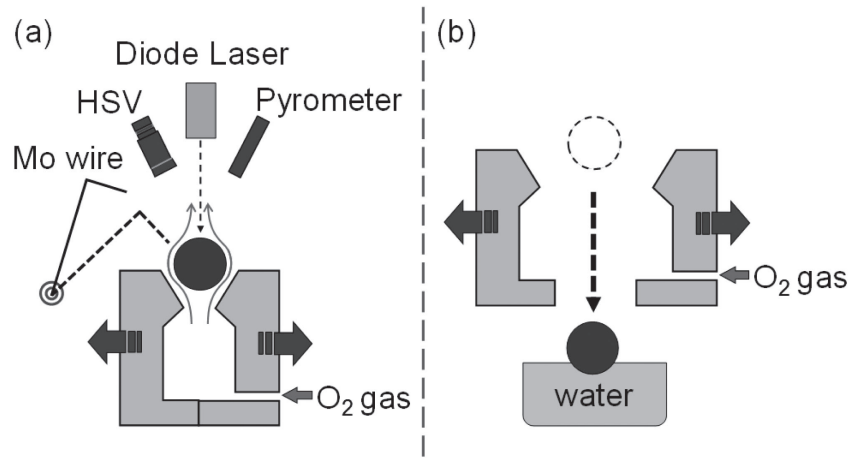

Fig. 2 Schematic of aerodynamic levitator. The levitated melt can be nucleated at given undercooled level by (a) contacting with Mo wire or by (b) dropping it into water bath through a splitting the gas jet nozzle. 


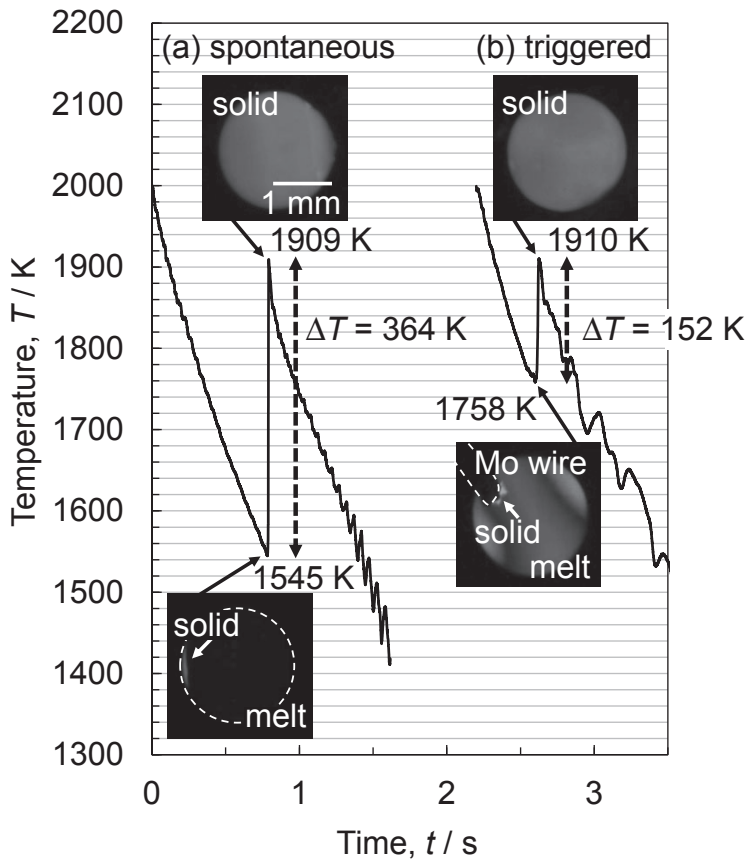

Fig. 3 Typical cooling curves of $\mathrm{DyMnO}_{3}$ samples nucleated from the undercooled melt (a) spontaneously and (b) forcibly by triggering with Mo wire.

て自発的に核生成し，それに伴うリカレッセンス後の最高到 達温度 (Post-recalescence temperature: $T_{\mathrm{pr}}$ ) は, $1909 \mathrm{~K}$ であっ た。 また， $T_{\mathrm{pr}}$ を基準にすると， $\Delta T=364 \mathrm{~K}$ となった。

一方， $1909 \mathrm{~K}$ 以下まで過冷却した浮遊液滴に Mo ワイヤを 接触させると (Fig. 3(b)), その部分から即座に核生成した. また, Mo ワイヤの接触によって $\Delta T$ を様々に変化させても, $T_{\mathrm{pr}}$ は $1910 \pm 3 \mathrm{~K}$ であったことから, $1910 \mathrm{~K}$ が $o-\mathrm{DyMnO}_{3}$ あ るいは $h-\mathrm{DyMnO}_{3}$ の融点とした.

Fig. 4, Fig. 5 は, $\Delta T$ を変化させた試料の代表的な粉末 XRD プロファイルと，それに対応する表面形態である.

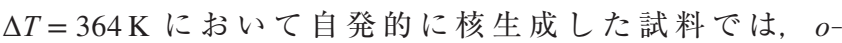
$\mathrm{DyMnO}_{3}(\boldsymbol{\Delta})$ と $h-\mathrm{DyMnO}_{3}(\square)$ の両相の存在が認められた。ま た表面形態は，樹枝状晶のいわゆるファセットデンドライト を連想させるものとなった。 $\Delta T$ が小さくなると, $o-\mathrm{DyMnO}_{3}$ の回折強度が低下し, $h-\mathrm{DyMnO}_{3}$ の回折強度が増加したが, 表面形態には大きな恋化はなかった。

ただし $\Delta T$ が $14 \mathrm{~K}$ まで小さくなると，ファセットデンドラ イトだけでなく，ミクロにファセットな表面形態を示す領域 が見られた。 Kumar ら ${ }^{5)}$ は，ファセット面は $h-\mathrm{LnMnO}_{3}$ に特 有な形態であり，樹枝状突起面は $o-\mathrm{LnMnO}_{3}$ に対応する形態 であると報告しており，本研究で得られた構成相と表面形態 の関係は，それにはよく対応している。

\section{4. 考察}

\section{1 核生成温度と構成相の関係}

粉末 XRDの結果 (Fig. 4) から, $\Delta T$ が小さい場合は $h-$ $\mathrm{DyMnO}_{3}$ の生成量が, $\Delta T$ が大きい場合は $o-\mathrm{DyMnO}_{3}$ の生成 量が多くなることが明らかとなった。しかし，いずれの $\Delta T$ に拈いても $h-\mathrm{DyMnO}_{3}$ または $o-\mathrm{DyMnO}_{3}$ の単相を得ること

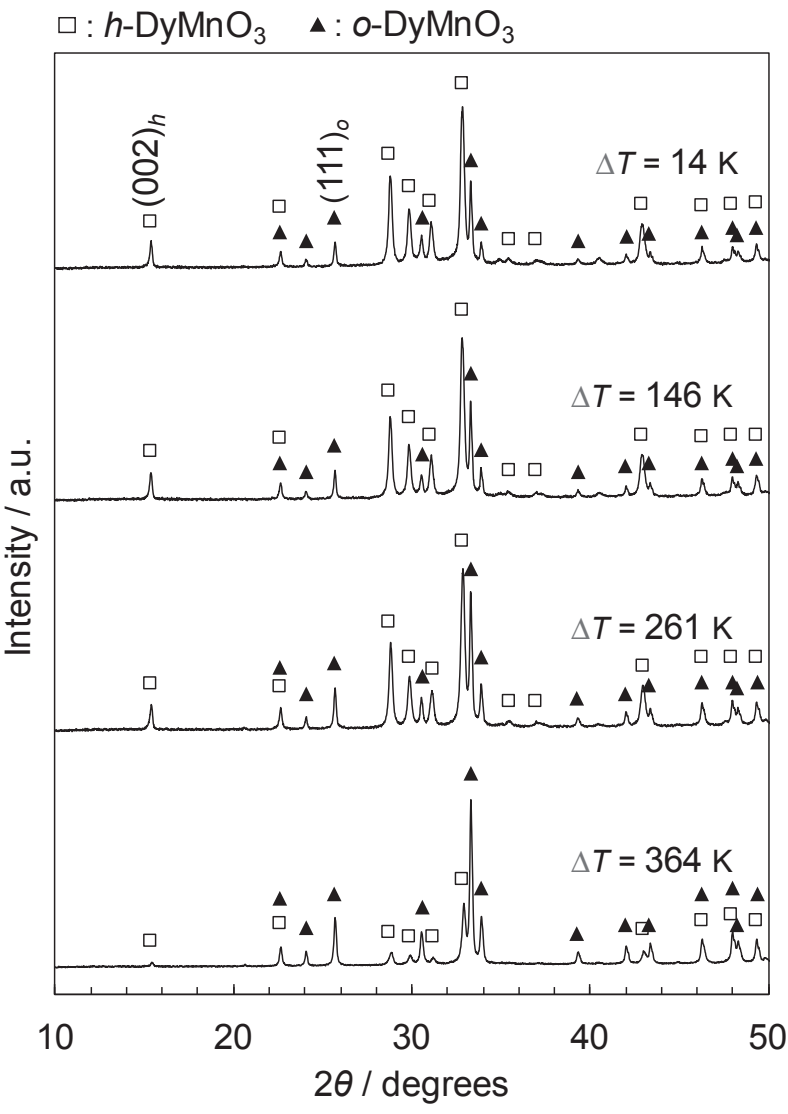

Fig. 4 Typical XRD patterns of the $\mathrm{DyMnO}_{3}$ samples nucleated from different $\Delta T$ by trigger system with Mo wire.
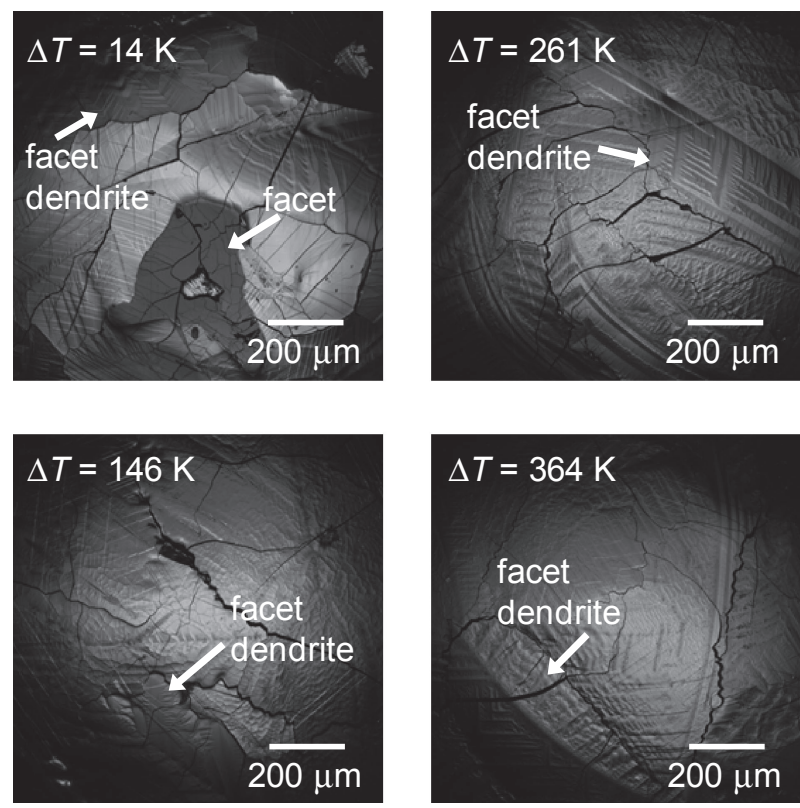

Fig. 5 Typical LSM images for the surface of the $\mathrm{DyMnO}_{3}$ samples nucleated from different $\Delta T$ by trigger system with Mo wire.

はできなかった。この関係をより明確にするために, $h-$ $\mathrm{DyMnO}_{3}$ と $o-\mathrm{DyMnO}_{3}$ の回折ピーク強度比 $\left(I_{h} / I_{o}\right)$ と $\Delta T$ との 関係を調べた。なお比較した回折ピークは，両者が重ならな い $h-\mathrm{DyMnO}_{3}$ の $(002)_{h}$ と $o-\mathrm{DyMnO}_{3}$ の $(111)_{o}$ とした。 その結 果を Fig. 6 に示す. $\Delta T$ が大きくなるにつれて, $I_{h} / I_{o}$ の值は 連続的に小さくなった後, $150 \mathrm{~K}<\Delta T<250 \mathrm{~K}$ において一旦 


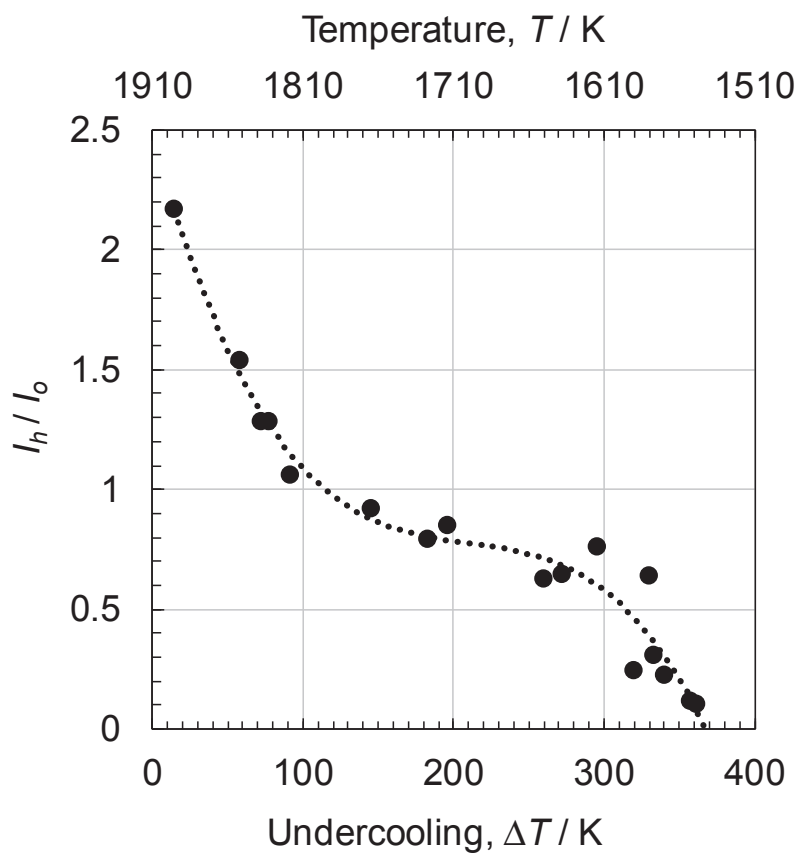

Fig. 6 Intensity ratio of XRD peaks for $(002)_{h}$ of $h$-DyMnO${ }_{3}$ and $(111)_{o}$ of $o-\mathrm{DyMnO}_{3}\left(I_{h} / I_{o}\right)$ as a function of undercooling level.

停滞し，その後再び小さくなっていった。 これは， $\Delta T<$ $150 \mathrm{~K}$ では $h-\mathrm{DyMnO}_{3}$ の生成が, $\Delta T>250 \mathrm{~K}$ では $o-\mathrm{DyMnO}_{3}$ の生成が顕著であり， $150 \mathrm{~K}<\Delta T<250 \mathrm{~K}$ が，その遷移領域 であることを表している。この結果は, $h-\mathrm{DyMnO}_{3}$ が準安定 相ではなく高温相であり, $h-\mathrm{DyMnO}_{3} \rightleftarrows o-\mathrm{DyMnO}_{3}$ の変態温 度 $T_{\text {tr }}$ が, この $150 \mathrm{~K}<\Delta T<250 \mathrm{~K}$ の範囲に対応する $1640-$ $1760 \mathrm{~K}$ に存在することを示唆する。 ただし, Fig. 4, Fig. 5 に 示したと㧍り，この温度範囲を大きく下回る $1545 \mathrm{~K}(\Delta T=$ $364 \mathrm{~K})$ で核生成した試料においても $h-\mathrm{DyMnO}_{3}$ が生成してい ることから, $\mathrm{DyMnO}_{3}$ 組成の試料を過冷却凝固させた際の $o^{-}$ $\mathrm{DyMnO}_{3}$ と $h-\mathrm{DyMnO}_{3}$ の相選択の律速過程は, $h-\mathrm{DyMnO}_{3} \rightleftarrows$ $o-\mathrm{DyMnO}_{3}$ の相変態ではなく, $o-\mathrm{DyMnO}_{3}$ と $h-\mathrm{DyMnO}_{3}$ のそ れぞれの核生成頻度であることも示唆される。またこれらを 総ずると, Fig. 6 において $h-\mathrm{DyMnO}_{3} \rightleftarrows o-\mathrm{DyMnO}_{3}$ の遷移温 度範囲が $1640-1760 \mathrm{~K}(150 \mathrm{~K}<\Delta T<250 \mathrm{~K})$ と広いのは, リカ レッセンス後の冷却過程における $o-\mathrm{DyMnO}_{3}$ の核生成と, $h-$ $\mathrm{DyMnO}_{3} \rightleftarrows o-\mathrm{DyMnO}_{3}$ の固相変態が相互に影響しているため と考えられる。

そこで, $o-\mathrm{DyMnO}_{3}$ と $h-\mathrm{DyMnO}_{3}$ の核生成頻度の競合関係 を独立して明らかにすべく，浮遊液滴を過冷却状態を含む 様々な温度から水中落下させて, 急冷凝固を試みた。 Fig. 7 に, 得られた試料の代表的な粉末 XRD パターンを示す. またTable 1 は, 浮遊液滴を水中落下させたときの温度と 構成相の関係である。浮遊液滴を, $1666 \mathrm{~K}(\Delta T=244 \mathrm{~K})$ 以 上から水中落下させたときは, $h-\mathrm{DyMnO}_{3}$ 単相となるが, 1576-1650 K $(260 \mathrm{~K}<\Delta T<334 \mathrm{~K})$ から落下させたときは, $o^{-}$ $\mathrm{DyMnO}_{3}$ と $h-\mathrm{DyMnO}_{3}$ の両相が生成した。このことから, $h-$ $\mathrm{DyMnO}_{3}$ は低過冷却度でも生成するのに対して, $o-\mathrm{DyMnO}_{3}$ は $1650 \mathrm{~K}$ 以下 $(\Delta T>260 \mathrm{~K})$ になると初めて核生成することが わかった。

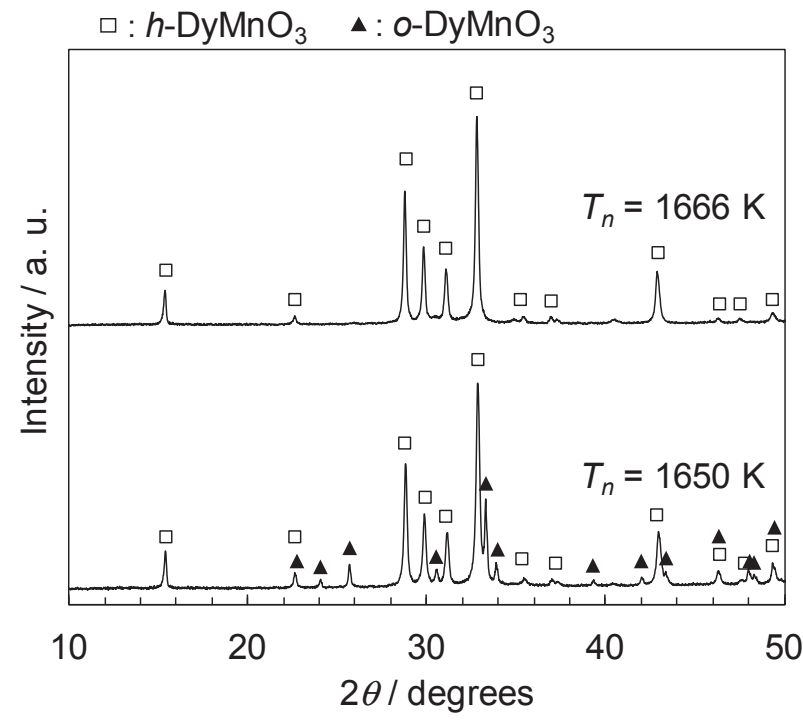

Fig. 7 Typical XRD patterns of the $\mathrm{DyMnO}_{3}$ samples quenched from the undercooling state into water bath.

Table 1 Relation between quenched temperature and phase constitution.

\begin{tabular}{cc}
\hline \begin{tabular}{c} 
quenched temperature $[\mathrm{K}]$ \\
\hline \hline 1920
\end{tabular} & phase constitution \\
\hline 1854 & \\
\hline 1820 & \\
\hline 1790 & \\
\hline 1765 & \\
\hline 1746 & \\
\hline 1666 & \\
\hline 1650 & \\
\hline 1649 & \\
\hline 1622 & \\
\hline 1612 &
\end{tabular}

\section{$4.2 h-\mathrm{DyMnO}_{3}$ および $o-\mathrm{DyMnO}_{3}$ 生成の律速過程}

前節に示した急冷実験からは, $\Delta T<244 \mathrm{~K}(T>1666 \mathrm{~K})$ で は $h-\mathrm{DyMnO}_{3}$ のみ核生成するが, $\Delta T>244 \mathrm{~K}(T<1666 \mathrm{~K})$ に なると $h-\mathrm{DyMnO}_{3}$ 以外に $o-\mathrm{DyMnO}_{3}$ も生成することがわ かった，核生成の観点からすれば，このようなことが生ずる 原因として, $h-\mathrm{DyMnO}_{3}$ は, $o-\mathrm{DyMnO}_{3}$ よりも融点が高く, かつ, 固液界面エネルギーが大幅に小さいことが挙げられ る. 本節ではこの観点から, 両相の核生成の活性化エネル ギーの導出を試みた。

核生成の古典論に従えば，臨界核生成の活性化エネルギー $\Delta G_{\mathrm{n}}^{*}$ は次式で与えられる. 


$$
\Delta G_{\mathrm{n}}^{*}=\frac{16 \pi \gamma_{\mathrm{sl}}^{3}}{3 \Delta G_{\mathrm{V}}^{2}} f(\theta)
$$

ここで， $\gamma_{\mathrm{s} 1}$ は固液界面エネルギー， $\Delta G_{\mathrm{V}}$ は体積ギブスエネ ルギーである。また， $f(\theta)$ は不均一核形成の触媒作用を表す 係数であり, $\theta$ は接触角に依存し次式で与えられる.

$$
f(\theta)=\frac{1}{4}\left(2-3 \cos \theta+\cos ^{3} \theta\right)
$$

Turnbull $^{6)}$ と Spaepen ${ }^{7)}$ は, $\gamma_{\mathrm{sl}}$ は固液界面でのエントロピー変 化に関係しているとして，次のように定式化した。

$$
\gamma_{\mathrm{sl}}=\frac{\alpha \Delta S_{\mathrm{f}} T}{\left(N_{\mathrm{A}} V_{\mathrm{m}}^{2}\right)^{\frac{1}{3}}}
$$

ここで, $N_{\mathrm{A}}, V_{\mathrm{m}}, \Delta S_{\mathrm{f}}, T, \alpha$ はそれぞれアボガドロ数, モル 体積, 融解エントロピー, 温度, Turnbull 係数6)である. $\alpha$ は 結晶構造に依存するとされているが, 多くは 0.5 前後10-15)で あることから, Kuribayashi ら ${ }^{16)}$ は, 式 ( 3 ) は酸化物にも適 用できると仮定し，さらに $\Delta G_{\mathrm{V}}=\Delta S_{\mathrm{f}} \Delta T$ と近似することに より，次式を得た。

$$
\Delta G_{\mathrm{n}}^{*} \propto \frac{\Delta S_{\mathrm{f}} T^{3}}{V_{\mathrm{m}}^{2}(\Delta T)^{2}} f(\theta)
$$

また彼らはFig. 8 に示すように, 凝固後の冷却曲線を核生成 した時間まで外挿したときの温度と核生成温度 $T_{\mathrm{n}}$ の差から, $h-\mathrm{LnFeO}_{3}$ と $o-\mathrm{LnFeO}_{3}$ の限界過冷却度 $\Delta T_{\text {hyp }}$ (hyper cooling limit)を得て, 次式より $\Delta S_{\mathrm{f}}$ を求めた.

$$
\Delta T_{\text {hyp }}=\frac{\Delta H_{\mathrm{f}}}{C_{\mathrm{p}}}=\frac{\Delta S_{\mathrm{f}} T}{C_{\mathrm{p}}}
$$

ここで, $\Delta H_{\mathrm{f}}$ は熱容量, $\Delta C_{\mathrm{p}}$ は定圧比熱であり, Einsteinの 格子比熱式に基づき $125 \mathrm{Jmol}^{-1} \mathrm{~K}^{-1}$ とされた16). また得られ た $\Delta T_{\text {hyp }}$ から, 両相について核形成の活性化エネルギーを求 め, 両相の融点差が臨界值を越える場合に, ダブルリカレッ センスが生ずることを示した ${ }^{16)}$.

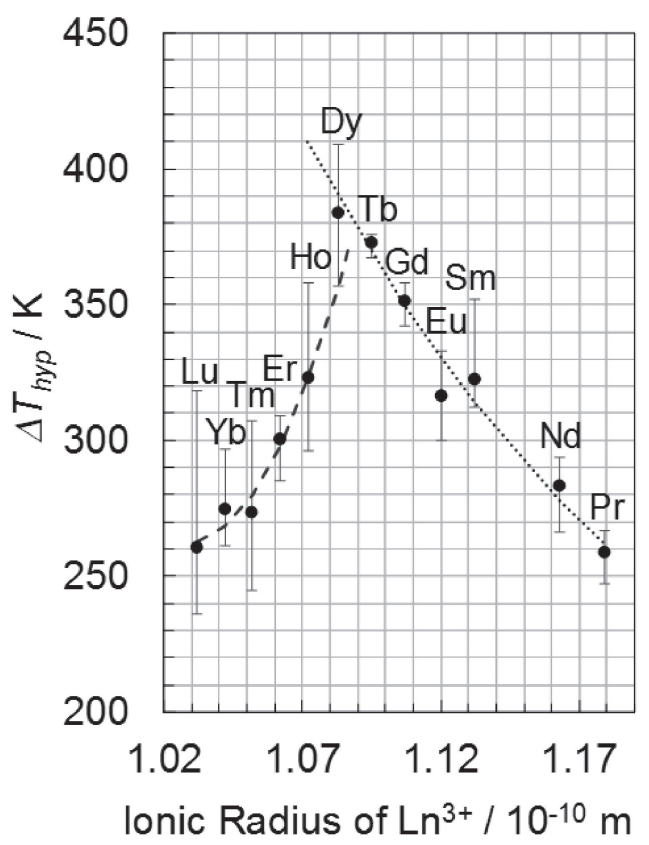

Fig. 9 は, 同手法を $h-\mathrm{DyMnO}_{3}$ と $o-\mathrm{DyMnO}_{3}$ に適用して求 めた $\Delta T_{\text {hyp }}$ と $\Delta S_{\mathrm{f}}$ である。ただし, $\mathrm{DyMnO}_{3}$ 組成試料におい ては, いずれの $\Delta T$ から核生成させた場合であっても， $h-$ $\mathrm{DyMnO}_{3}$ および $o-\mathrm{DyMnO}_{3}$ の単相を得ることはできず(Fig. 4 参照), かつ, 温度-時間曲線では, それらの単独の融点を識 別することが困難であったため, このデー夕から直接 $h-\mathrm{DyMnO}_{3}$ および $o-\mathrm{DyMnO}_{3}$ の $\Delta T_{\mathrm{hyp}}$ を見積もることはで きなかった。 そこで, $h-\mathrm{DyMnO}_{3}$ については $\mathrm{Lu}$ 側から, $\mathrm{DyMnO}_{3}$ については La 側からの外挿值により $\Delta T_{\mathrm{hyp}}$ を求め た. Table 2 は, このようにして得られた $h-\mathrm{DyMnO}_{3}$ とo$\mathrm{DyMnO}_{3}$ の $\Delta S_{\mathrm{f}}, V_{\mathrm{m}}$ および計算に用いた平衡融点 $T_{\mathrm{E}}$ である.

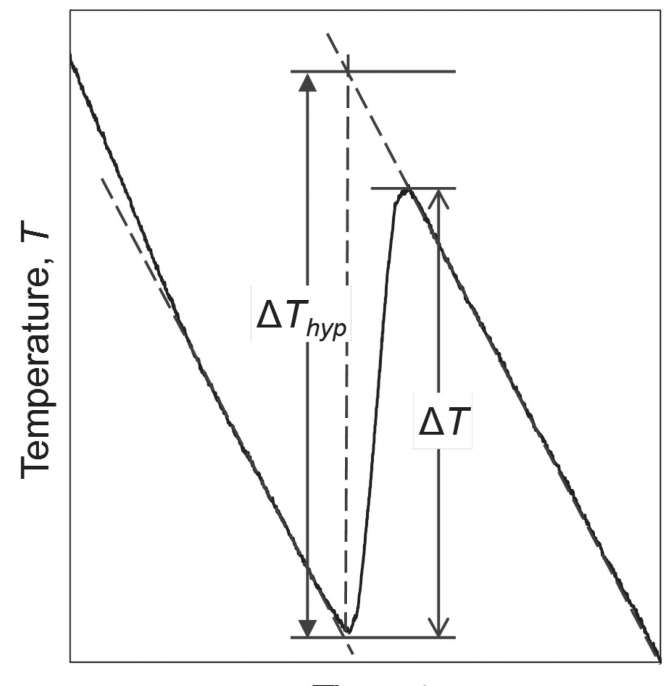

Time, $t$

Fig. 8 Schematic of estimation for $\Delta T_{\text {hyp }}$ under assumption that heat removal rate is constant during solidification.

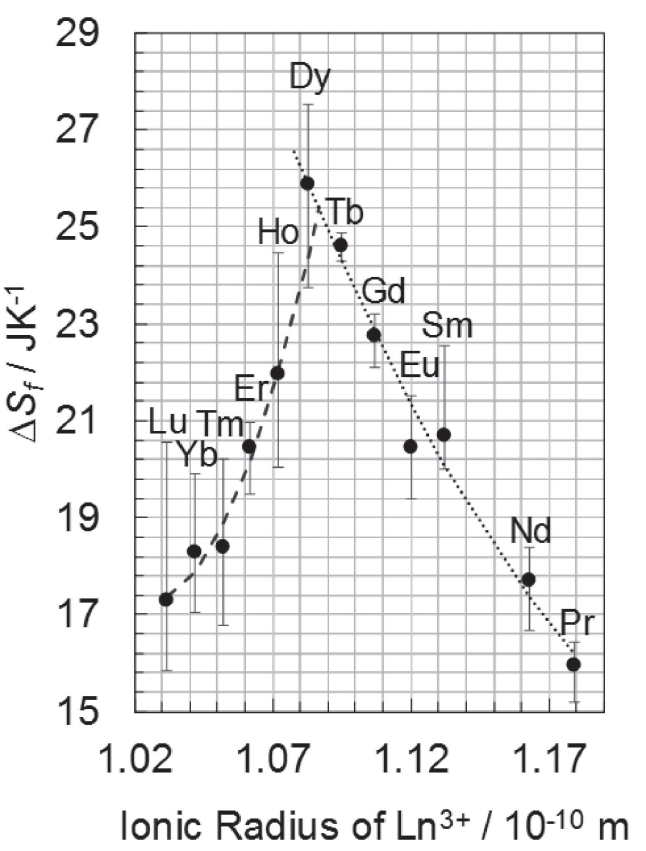

Fig. $9 \Delta T_{\text {hyp }}$ and $\Delta S_{\mathrm{f}}$ vs. ionic radius of $\mathrm{Ln}^{3+}$ : Dashed and dotted lines are curves fitted by power series for the data from $\mathrm{Lu}^{3+}$ to $\mathrm{Ho}^{3+}$ and from $\mathrm{Pr}^{3+}$ to $\mathrm{Tb}^{3+}$, respectively. Since it is difficult to determine the melting point of $h-\mathrm{DyMnO}_{3}$ and the hypothetical melting point of $o-\mathrm{DyMnO}$ from the temperature-time relationship or HSV image, $\Delta T_{\text {hyp }}$ was calculated by extrapolating the fitted curves from the $\mathrm{Lu}$ side for $h$-DyMnO 3 and from the $\mathrm{La}$ side for $o-\mathrm{DyMnO}_{3}$. 
なお， $h-\mathrm{DyMnO}_{3}$ は高温相であることが示唆されたことに加 え, いずれの $\Delta T$ から核生成した場合でも $T_{\mathrm{pr}} \approx 1910 \mathrm{~K}$ と なったことから, この温度を $h-\mathrm{DyMnO}_{3}$ の平衡融点であると した。また， $\mathrm{HSV}$ 画像において, $h-\mathrm{DyMnO}_{3}$ と $o-\mathrm{DyMnO}_{3}$ の 核生成挙動の区別が困難であったのは, 両相の平衡融点が非 常に近いためであることを踏まえて, $o-\mathrm{DyMnO}_{3}$ の平衡融点 を $1890 \mathrm{~K}$ と見積もった。モル体積は $h-\mathrm{DyMnO}_{3}$ の方が大き いため, 両相の $T_{\mathrm{E}}$ における $\Delta S_{\mathrm{f}}$ は, $h-\mathrm{DyMnO}_{3}$ の方が小さ くなる.また式( 4 ) からわかるように, $\Delta G_{\mathrm{n}}^{*}$ も小さくなる.

これらの条件を基に, 式( 4 ) から $h-\mathrm{DyMnO}_{3}$ と $o-\mathrm{DyMnO}_{3}$ について $\Delta G_{\mathrm{n}}^{*}$ と $T_{\mathrm{n}}$ の関係を求めると, 両相の $f(\theta)$ が等しい 場合は, $\Delta G_{\mathrm{n}}^{*}$ は常に $h-\mathrm{DyMnO}_{3}$ において小さく, したがって 核生成は $h-\mathrm{DyMnO}_{3}$ が先行する結果となった. Fig. 10 は, その計算例として, 両相ともに優先サイトがない $(f(\theta)=1.0)$ 場合の比較および, $O-\mathrm{DyMnO}_{3}$ については助変数として $f_{o}(\theta)=0.02 \sim 1.0$ に変化させた場合の結果である.すなわち, $o-\mathrm{DyMnO}_{3}$ が生成するためには, $f(\theta)$ が $h-\mathrm{DyMnO}_{3}$ よりも小 さいことが条件であり，それは先行して生成した $h-\mathrm{DyMnO}_{3}$ の界面を優先サイトとする不均一核生成によってのみ起こる

\section{ことが導かれる.}

この場合, $\mathrm{LnFeO}_{3}$ 系と異なるのは, 先行して核生成した $h-\mathrm{DyMnO}_{3}$ は, $o-\mathrm{DyMnO}_{3}$ の核生成後に溶解することなく, $o-\mathrm{DyMnO}_{3}$ に (拡散) 相変態すると考えられる点である.

Table 2 Entropy of fusion $\Delta S_{\mathrm{f}}$, molar volume $V_{\mathrm{m}}$ and equilibrium temperature $T_{\mathrm{E}}$ of $h-\mathrm{DyMnO}_{3}$ and $o-\mathrm{DyMnO}_{3}$.

\begin{tabular}{lccc}
\hline & $\Delta S_{f}\left[\mathrm{Jmol}^{-1} \mathrm{~K}^{-1}\right]$ & $V_{m}\left[\mathrm{~m}^{3} \mathrm{~mol}^{-1}\right]$ & $T_{E}[\mathrm{~K}]$ \\
\hline \hline$h-\mathrm{DyMnO}_{3}$ & 24.4 & $3.90 \times 10^{-5}$ & 1910 \\
\hline$o-\mathrm{DyMnO}_{3}$ & 25.9 & $3.53 \times 10^{-5}$ & 1890 \\
\hline
\end{tabular}

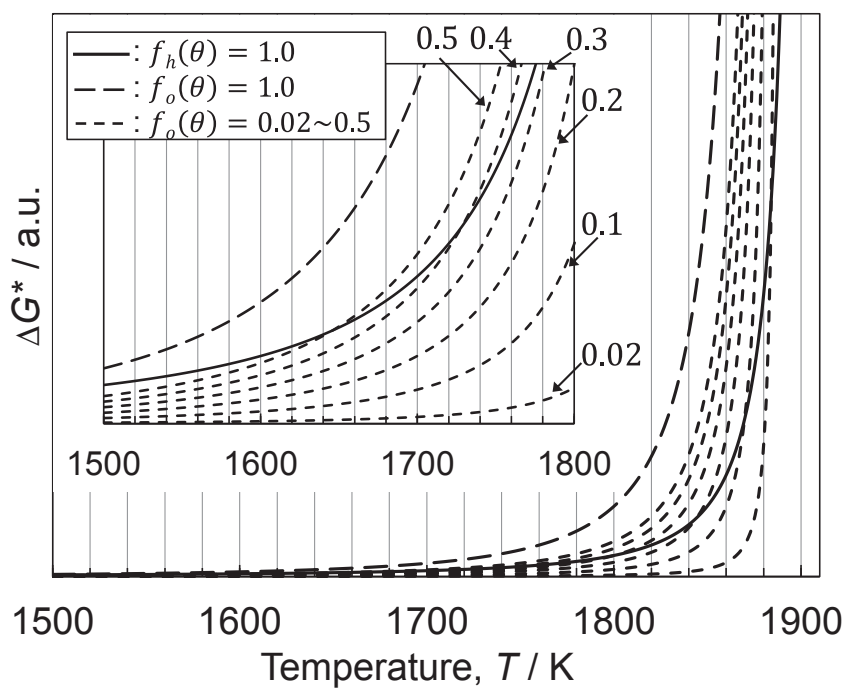

Fig. 10 Activation energy for forming critical nuclei of $h-\mathrm{DyMnO}_{3}$ and $o-\mathrm{DyMnO}_{3}$ expressed as a function of the degree of undercooling. Here, $f(\theta)$, the catalytic capacity for heterogeneous nucleation, was assumed to be 1.0 for $h-\mathrm{DyMnO}_{3}$ and was varied from 0.02 to 1.0 as an auxiliary variable for $o-\mathrm{DyMnO}_{3}$.

\section{5. 結 論}

$\mathrm{DyMnO}_{3}$ 試料を, $\mathrm{ADL}$ を用いて浮遊溶融させて, 任意の過 冷却度 $\Delta T$ でMo ワイヤを接触させる, あるいは水中に落下 させることにより強制的に核生成・凝固させることで, $\mathrm{DyMnO}_{3}$ 組成における $o-\mathrm{DyMnO}_{3}$ と $h-\mathrm{DyMnO}_{3}$ の共存原因を 検討した。その結果, $\Delta T<244 \mathrm{~K}(T>1666 \mathrm{~K})$ で核生成させ た場合は $h-\mathrm{DyMnO}_{3}$ のみが, $\Delta T>244 \mathrm{~K}(T<1666 \mathrm{~K})$ で核生 成させた場合は $h-\mathrm{DyMnO}_{3}$ に加えて $o-\mathrm{DyMnO}_{3}$ も生成するこ とがわかった.この点を明らかにする目的で, $o-\mathrm{DyMnO}_{3}$ と $h-\mathrm{DyMnO}_{3}$ の核生成の活性化エネルギーについて, Turnbull と Spaepenのモデルによる計算を行ったところ, 過冷却融液 からの核生成では, 常に $h-\mathrm{DyMnO}_{3}$ が先行し, $o-\mathrm{DyMnO}_{3}$ は, $h-\mathrm{DyMnO}_{3}$ と融液の界面を優先サイトとすることより初 めて生成が可能になることが示唆された。

\section{Nomenclature lists}

$G$ : 定圧下におけるギブスエネルギーの温度依存性 $[\mathrm{J}]$ $G_{o}: o-\mathrm{DyMnO}_{3}$ の生成ギブスエネルギー $[\mathrm{J}]$ $G_{h}: h-\mathrm{DyMnO}_{3}$ の生成ギブスエネルギー $[\mathrm{J}]$ $T_{\mathrm{tr}}:$ 固相変態温度 $[\mathrm{K}]$ $\Delta T:$ 過冷却度 $[\mathrm{K}]$

$T_{\mathrm{pr}}$ : リカレッセンス後の最高到達温度 $[\mathrm{K}]$ $I_{h}: h-\mathrm{DyMnO}_{3}$ の $(002)_{h}$ の回折ピーク強度 $I_{o}: o-\mathrm{DyMnO}_{3}$ の $(111)_{o}$ の回折ピーク強度 $\Delta G_{\mathrm{n}}^{*}:$ 臨界核生成の活性化エネルギー $[\mathrm{J}]$ $\gamma_{\mathrm{sl}}$ : 固液界面エネルギー $\left[\mathrm{Jm}^{-2}\right]$

$\Delta G_{\mathrm{V}}:$ 体積ギブスエネルギー $[\mathrm{J}]$

$\theta$ : 接触角 $\left[{ }^{\circ}\right]$

$f(\theta)$ : 不均一核形成の触媒作用を表す係数

$N_{\mathrm{A}}$ : アボガドロ定数 $: 6.02 \times 10^{23}\left[\mathrm{~mol}^{-1}\right]$

$V_{\mathrm{m}}:$ モル体積 $\left[\mathrm{m}^{3} \mathrm{~mol}^{-1}\right]$

$\Delta S_{\mathrm{f}}$ : 融解エントロピー $\left[\mathrm{JK}^{-1} \mathrm{~mol}^{-1}\right]$

$\alpha$ : Turnbull 係数 6 )

$T_{\mathrm{n}}:$ 核生成温度 $[\mathrm{K}]$

$\Delta T_{\text {hyp }}$ ：限界過冷却度 $[\mathrm{K}]$

$\Delta H_{\mathrm{f}}$ : 熱容量 $\left[\mathrm{Jmol}^{-1}\right]$

$C_{\mathrm{p}}:$ 定圧比熱 $\left[\mathrm{JK}^{-1} \mathrm{~mol}^{-1}\right]$

$T_{\mathrm{E}}$ : 平衡融点 $[\mathrm{K}]$

文献

1) T. Kimura, T. Goto, H. Shintani, H. Ishizaka, T. Arima and Y. Tokura: Nature 426 (2003) 55-58.

2) J.-S. Zhou, J.B. Goodenough, J.M. Gallardo-Amores, E. Morán, M.A Alario-Franco and R. Caudillo: Phys. Rev. B 74 (2006) 014422.

3) B.B. Van Aken, T.T.M. Palstra, A. Filippetti and N.A. Spaldin: Nat. Mater. 3 (2004) 164-170.

4) H.L.J. Yakel, W.C. Koehler, E.F. Bertaut and E.F. Forrat: Acta Crystallogr. 16 (1963) 957-962.

5) M.S.V. Kumar, N. Higaki, K. Kuribayashi, T. Hibiya and S. Yoda: J. Am. Ceram. Soc. 94 (2011) 281-288.

6) D. Turnbull and R.E. Cech: J. Appl. Phys. 21 (1950) 804-810.

7) F. Spaepen: Acta Metall. 23 (1975) 729-743. 
8) J. Takasaki, K. Kuribayashi and S. Ozawa: Mater. Trans. 59 (2018) 469-474.

9) G. Szabo and R.A. Paris: C. R. Acad. Sci. Paris, Ser. C 268 (1969) 513-516

10) K. Kuribayashi, S. Shirasawa, Y. Hayasaka, S. Shiratori and S. Ozawa: J. Am. Ceram. Soc. 103 (2020) 4822-4831.

11) B.B. Laird: J. Chem. Phys. 115 (2001) 2887-2888.

12) J.Q. Broughton and G.H. Gilmer: J. Chem. Phys. 84 (1986) $5759-5768$
13) L.V. Mikheev and A.A. Chernov: J. Crys. Growth 112 (1991) 591-596.

14) J.J. Hoyt, M. Asta and A. Karma: Mater. Sci. Eng. R41（2003 121-163.

15) D.Y. Sun, M.I. Mendelev, C.A. Becker, K. Kudin, T. Haxhimali, M Asta, J.J. Hoyt, A. Karma and D.J. Srolovitz: Phys. Rev. B 73 (2006) 024116.

16) K. Kuribayashi, H. Kato, K. Nagayama, Y. Inatomi and M.S.V. Kumar: J. Appl. Phys. 117 (2015) 154905. 